\title{
Outbreak of haemolytic uraemic syndrome due to Shiga toxin-producing Escherichia coli O104:H4 among French tourists returning from Turkey, September 2011
}

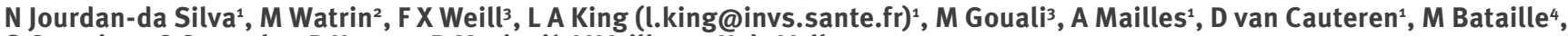

S Guettier ${ }^{4}$, C Castrale ${ }^{5}$, P Henry ${ }^{5}$, P Mariani ${ }^{6}$, V Vaillant ${ }^{1}, \mathrm{H}$ de Valk ${ }^{1}$

1. French Institute for Public Health Surveillance (Institut de veille sanitaire), St Maurice, France

2. Regional Office of the French Institute for Public Health Surveillance, Caen, France

3. Institut Pasteur, National Reference Centre for Escherichia coli and Shigella, Paris, France

4. University Hospital of Caen, Neurology department, Caen, France

5. University Hospital of Caen, Nephrology department, Caen, France

6. Laboratory associated to the National Reference Centre for Escherichia coli and Shigella, Robert Debré Hospital, Paris, France

Jourdan-da Silva N, Watrin M, Weill FX, King LA, Gouali M, Mailles A, van Cauteren D, Bataille M, Guettier S, Castrale C, Henry P, Mariani P, Vaillant V, de Valk H. Outbreak of haemolytic uraemic syndrome due to Shiga toxin-producing Escherichia coli 0104:H4 among French tourists returning from Turkey, September 2011. Euro Surveill. 2012;17(4):pii=20065. Available online: http://www.eurosurveillance.org/ViewArticle.aspx?Articleld=20065

Article published on 26 January 2012

Eight cases of diarrhoea, including two cases of haemolytic uraemic syndrome (HUS), were identified among 22 French tourists who travelled to Turkey in September 2011. A strain of Escherichia coli 0104: $\mathrm{H}_{4}$ stx2-positive, eae-negative, hlyA-negative, aggR-positive, ESBL-negative was isolated from one HUS case. Molecular analyses show this strain to be genetically similar but not indistinguishable from the $E$. coli 0104:H4 2011 outbreak strain of France and Germany. Although the source of infection was not identified, we conclude that the HUS cases had probably been infected in Turkey.

On 30 September 2011, the University Hospital of Caen in western France informed the local health authorities of two cases of post-diarrhoeal haemolytic uraemic syndrome (HUS) in adults returning from an organised bus tour in Turkey that had taken place between 4 and 17 September 2011. Both cases were women in their 6os. They had not known each other prior to their journey to Turkey. Diarrhoea onset was 15 September for both cases. They were hospitalised following their return from Turkey and HUS was diagnosed on 20 and 26 September 2011. Initial information obtained from the concerned travel agency indicated the occurrence of additional cases of diarrhoea among other members of this travel group during the trip to Turkey.

\section{Epidemiological investigation}

A case was defined as a person with diarrhoea, bloody diarrhoea or HUS, with a date of symptom onset between 4 September and 2 October 2011, who was a member of the group having travelled to Turkey between 4 and 17 September 2011. A case of HUS was defined as acute renal failure and either microangiopathic haemolytic anaemia and/or thrombocytopenia.
The tour operator was contacted to identify any additional cases among individuals of groups who subsequently travelled on the same bus tour.

All 22 travellers of the group were interviewed using a standardised semi-structured questionnaire exploring symptoms, food consumption including sprouts, activities undertaken during the trip to Turkey, and contact with animals or other cases of diarrhoea in the seven days before symptom onset.

\section{Case description}

As of 4 October 2011, six additional cases were identified, bringing the total number of cases to eight. Among the eight cases, six were women and two were men with a median age of 64 years (range: 51-71 years). Five cases presented with diarrhoea, one case initially with diarrhoea and a second episode of bloody diarrhoea four days later, and two cases with bloody diarrhoea evolving into HUS. Cases had symptom onset between 6 and 15 September with an initial group of five cases occurring on 6 and 7 September and three cases occurring later during the trip (Figure 1). One case consulted a hospital emergency room for bloody diarrhoea during the trip and was not admitted. Both HUS cases were hospitalised following their return to France. One HUS case was discharged after five days of hospitalisation while the second case, who had a transient ischemic attack, was discharged after nine days of hospitalisation.

The group's two-week bus itinerary in Turkey took them from Istanbul to Ankara, Cappadocia, Aksaray, Konya, Pamukkale, Aphrodesia, Kudsadai, Priene, Miletus, Didymus, Izimir, Selçuk, Pergamum and Bursa. Due to the relatively long stay in Turkey, and the fact that the group stayed in nine different hotels and repeatedly 
ate similar foods in numerous restaurants, often with buffet style meals, we were unable to identify a specific food that might have been associated with illness. While group members could usually remember having eaten a certain food item, they could not remember on what date, how often or during which specific meals they had consumed this item. No member of the group reported having eaten sprouts during the trip to Turkey or before departure to Turkey.

Following the initial interview, a second questionnaire focusing specifically on food items eaten at the airport before boarding the plane, during the flight from Paris to Istanbul on 4 September and during the first two days of the tour was undertaken. The objectives were to exclude the hypothesis of contamination before arrival in Turkey and to identify a food consumed during the first 48 hours after arrival in Turkey that could have explained the five initial cases. Information on the menus served during the flight from Paris to Istanbul was obtained from the airline's catering company. Group members reported no common meal or food shared before boarding the plane in Paris and none brought food to the airport to share among the group. Two menus were available during the flight with a choice of poultry or smoked fish as a main course. Neither menu was common to all cases. The group members had difficulty remembering specific foods items served during the 48 hours after arrival in Turkey. These data were not sufficiently robust for further analysis.

\section{Microbiological and serological investigation}

Shiga toxin-producing Escherichia coli (STEC) 0104: $\mathrm{H}_{4}$ possessing the gene stx 2 but not the genes coding for intimin (eae) and haemolysin ( $h l y A)$ was isolated from one of the HUS patients. The strain was also negative for the gene coding EAST1 toxin (astA) and positive for the $\operatorname{agg} A$ gene which encodes the aggregative

\section{FIGURE 1}

Cases of haemolytic uraemic syndrome due to Shiga toxinproducing Escherichia coli O104:H4, diarrhoea or bloody diarrhoea, by date of symptom onset, among French tourists returning from Turkey, September $2011(\mathrm{n}=8)$

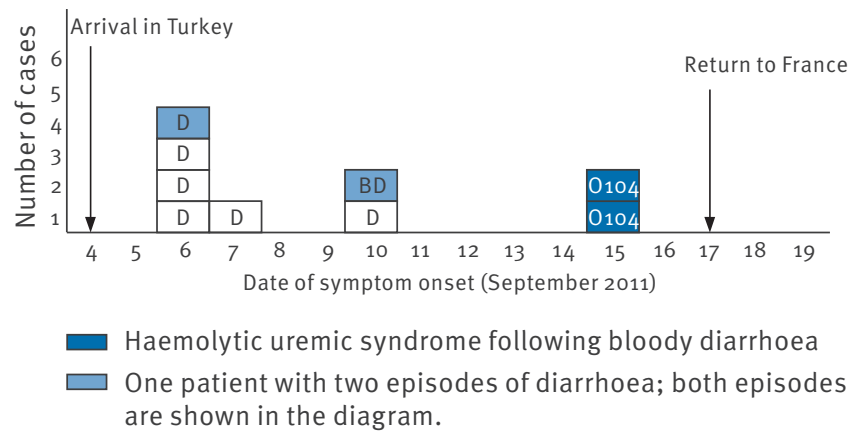

BD: bloody diarrhoea; D: diarrhoea; 0104: confirmed Escherichia coli $\mathrm{O}_{104}: \mathrm{H}_{4}$ infection. adherence fimbriae type I (AAF/I). Analyses on the stool of the second HUS patient were negative for STEC 0104: $\mathrm{H}_{4}$. The STEC 0104: $\mathrm{H}_{4}$ isolate had the following antibiotic resistance profile: ampicillin-resistant $(R)$, streptomycin $R$, sulphonamide $R$, trimethoprim $R$, cotrimoxazole $R$, tetracycline $R$, nalidixic acid $R$, cefotaximesensitive (S), ceftazidime $S$, imipenem $S$, kanamycin $S$, gentamicin S, chloramphenicol $\mathrm{S}$, and ciprofloxacin S. Except the absence of an extended-spectrum betalactamase, the resistance profile of this isolate was similar to the profile of the strain involved in the recent STEC 0104: $\mathrm{H}_{4}$ outbreaks in Germany and Bordeaux in France linked to the consumption of sprouts in MayJune $2011[1,2]$.

The strain isolated from the HUS case returning from Turkey was compared by pulsed-field gel electrophoresis (PFGE) using $\mathrm{Xbal}$ and Notl [3] to STEC 0104:H4 stx2 strains isolated from two imported cases in France linked to the German 2011 outbreak, ten patients in the Bordeaux outbreak in 2011, and two sporadic cases isolated in France in 2004 and 2009 (Figures 2 and 3). Previous molecular analyses had shown the genetic relatedness of the Bordeaux and German 0104: $\mathrm{H}_{4}$ strains [1]. The $\mathrm{Xbal}$ - and Notl-PFGE profiles of the strain isolated from the HUS case returning from Turkey were close but not identical (differences in two bands for Xbal and in three bands for Notl) to those of the German and Bordeaux 0104:H4 2011 outbreak strains. PFGE also showed that the strain isolated from the patient returning from Turkey was unrelated to the two 0104:H4 stx2 aggR agg3A strains isolated previously in France in 2004 and 2009 [4].

In addition, both HUS cases had a positive serology for E. coli 0104 . Serological testing was performed by a line blot immunoassay using lipopolysaccharides of seven major serogroups of STEC $\left(0_{2} 6,0_{91}, 0_{103}\right.$, $\mathrm{O}_{111}, \mathrm{O}_{128}, \mathrm{O}_{145}, \mathrm{O}_{157}$ ) and of $\mathrm{O}_{104}$ (extracted from a clinical $0104: \mathrm{H}_{4}$ isolate) [5].

Biological samples were not systematically taken from non-HUS cases as they were no longer symptomatic at the time of the investigation. At the initiative of the treating physician, a stool sample was taken from one case and a serum sample from another, both 28 days after the start of diarrhoea. Both analyses were negative.

\section{Control measures}

Colleagues in other European countries were informed of this outbreak on 4 October via the Epidemic Intelligence Information System (EPIS) of the European Centre of Disease Prevention and Control (ECDC) and Early Warning Response System (EWRS) with the request to report any similar cases.

Germany reported the occurrence of two adult cases of infection with ESBL-negative STEC 0104: $\mathrm{H}_{4}$ stx2 among persons returning from Turkey in July and August 2011. They had developed bloody diarrhoea 11 days and 18 
after days after returning from Turkey, where both had stayed in Istanbul and one had additionally spent time at the Black Sea (personal communication, Dirk Werber, January 2012).
Moreover, Danish colleagues reported an STEC 0104: $\mathrm{H}_{4}$ stx2 infection in an adult with diarrhoea onset on 28 September, two days before the end of a month's stay

\section{FIGURE 2}

PFGE profiles $(\mathrm{XbaI})$ obtained from one STEC O104:H4 isolate from a French traveller returning from Turkey and other STEC O104:H4 outbreak isolates from France and Germany a and from various Escherichia coli O104 reference strains

\section{PFGE Xbal PFGE Xbal}

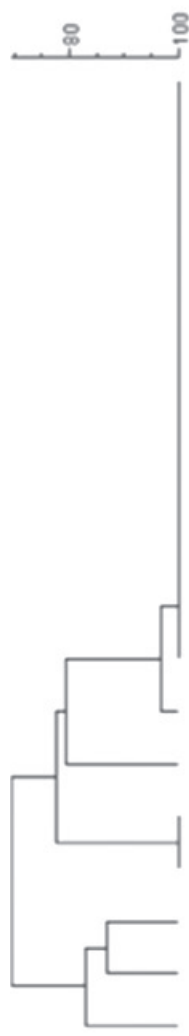

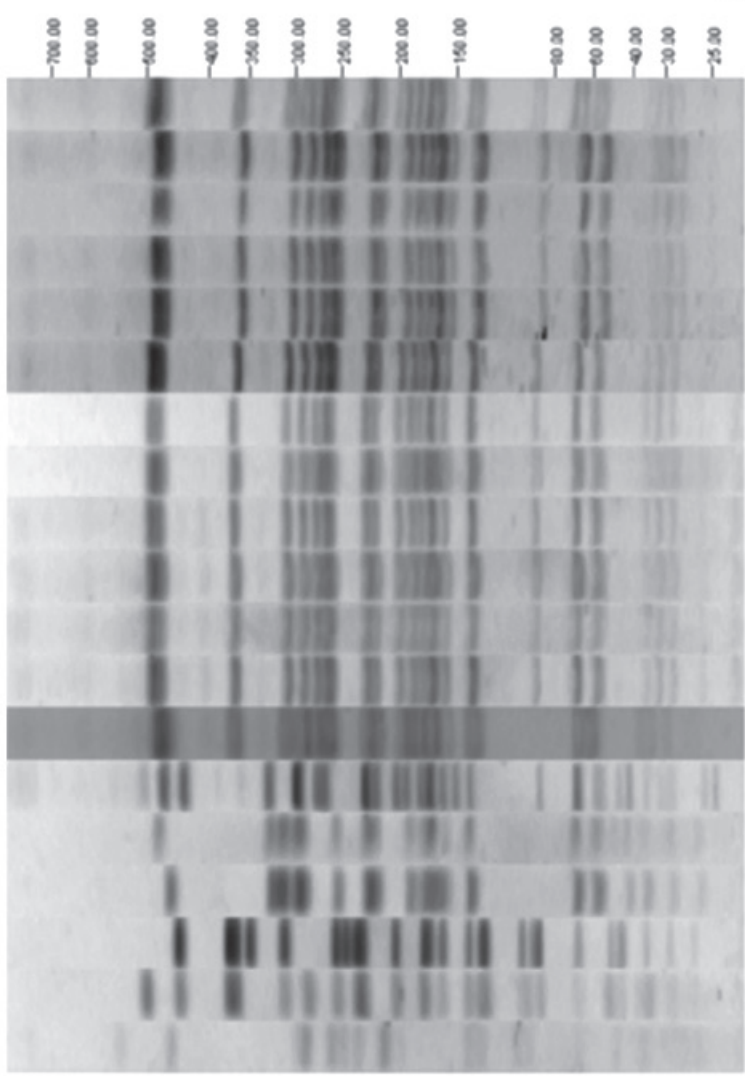

$\begin{array}{llll}\text { Ec11-4632.2 } & \text { Bordeaux 2011 } & \text { O104 } & \mathrm{H} 4 \\ \text { Ec11-4623 } & \text { Bordeaux 2011 } & 0104 & \mathrm{H} 4 \\ \text { Ec11-4404 } & \text { Bordeaux 2011 } & 0104 & \mathrm{H} 4 \\ \text { Ec11-4984 } & \text { Bordeaux 2011 } & 0104 & \mathrm{H} 4 \\ \text { Ec11-4988 } & \text { Bordeaux 2011 } & 0104 & \mathrm{H} 4 \\ \text { Ec11-6006 } & \text { Bordeaux 2011 } & 0104 & \mathrm{H} 4 \\ \text { Ec11-3677 } & \text { Germany 2011 } & 0104 & \mathrm{H} 4 \\ \text { Ec11-3798 } & \text { Germany 2011 } & 0104 & \mathrm{H} 4 \\ \text { Ec11-4522 } & \text { Bordeaux 2011 } & 0104 & \mathrm{H} 4 \\ \text { Ec11-5536 } & \text { Bordeaux 2011 } & 0104 & \mathrm{H} 4 \\ \text { Ec11-5537 } & \text { Bordeaux 2011 } & 0104 & \mathrm{H} 4 \\ \text { Ec11-5538 } & \text { Bordeaux 2011 } & 0104 & \mathrm{H} 4 \\ \text { Ec11-9450 } & \text { Turkey 2011 } & 0104 & \mathrm{H} 4 \\ \text { CRBIP14.5 } & \text { Reference strain } & 0104 & \mathrm{H} 4 \\ \text { Ec09-7901 } & \text { France 2009 } & 0104 & \mathrm{H} 4 \\ \text { Ec04-8351 } & \text { France 2004 } & 0104 & \mathrm{H} 4 \\ \text { CIP105999 } & \text { Reference strain } & 0104 & \mathrm{H} 21 \\ \text { CIP106042 } & \text { Reference strain } & 0104 & \mathrm{H} \text { ? } \\ \text { H519 } & \text { Reference strain } & 0104 & \mathrm{H} 12\end{array}$

PFGE: pulsed-field gel electrophoresis; STEC: Shiga toxin-producing Escherichia coli.

a Ten STEC 0104: $\mathrm{H}_{4}$ isolates from Bordeaux, France (2011), two STEC 0104:H4 isolates from Germany (2011), two STEC 0104: 44 isolates from France (2004 and 2009).

The dendrogram generated by BioNumerics version 6.5 software (Applied Maths, Sint-Martens-Latem, Belgium) shows the results of cluster analysis on the basis of PFGE fingerprinting.

Similarity analysis was performed using the Dice coefficient and clustering was done using the unweighted pair-group method with arithmetic averages (UPGMA).

\section{FIGURE 3}

PFGE profiles (NotI) obtained from the STEC O104:H4 isolates linked to the outbreak cases, France 2011

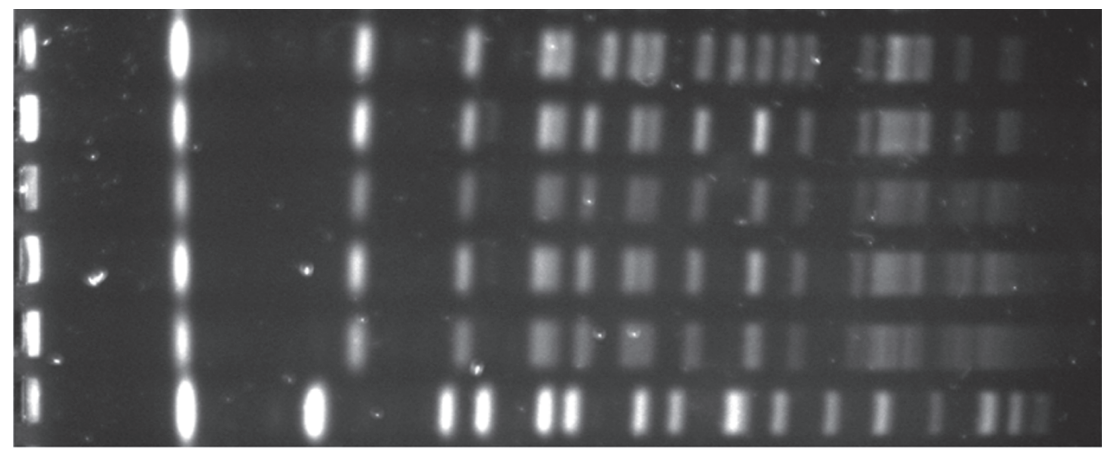

Ec11-9450 Turkey 2011 Escherichia coli O104:H4

Ec11-4986 Bordeaux 2011 Escherichia coli O104:H4

Ec11-4404 Bordeaux 2011 Escherichia coli 0104:H4

Ec11-3798 Germany 2011 Escherichia coli O104:H4

Ec11-3677 Germany 2011 Escherichia coli O104:H4

H9812 Salmonella enterica serotype Braenderup (marker)

PFGE: pulsed field gel electrophoresis; STEC: Shiga toxin-producing Escherichia coli. 
in private homes in Ankara (personal communication, Charlotte Kjelsø, January 2012).

Contact with the travel agency showed that none of the tourists having subsequently travelled on the same bus tour reported developing diarrhoea. As evidence suggested that this outbreak was limited to tourists from this single travel group, no particular control measures were put in place.

\section{Conclusions}

There is no evidence to link this STEC $0104: \mathrm{H}_{4}$ outbreak to the consumption of fenugreek sprouts, as was the case for the German and French outbreaks in May to June 2011 [6-9]. None of the 22 travel group members reported the consumption of sprouts before and during their trip to Turkey.

Microbiological or serological evidence of STEC 0104: $\mathrm{H}_{4}$ infection was only obtained for the two HUS cases. Considering that the median incubation period described for STEC $0104: \mathrm{H}_{4}$ is eight to nine days (range: two to 18 days) [10] and that these cases developed their symptoms 11 days after their arrival in Turkey, it is probable that they were infected during their stay in Turkey. In addition, these cases did not know each other before their trip to Turkey, they do not live in the same town and they consumed no common foods before or during their flight to Turkey, which provides further evidence in favour of this hypothesis. No source of contamination could be identified for these cases.

The fact that the six initial diarrhoea cases did not share a common food before or during the flight to Turkey suggests that they were infected following their arrival in Istanbul. However, their reported incubation period was much shorter than that of the HUS cases. Moreover, none were confirmed as STEC 0104: $\mathrm{H}_{4}$ infection. Thus, this cluster may have been due to another pathogen and may have been a distinct event not linked to the HUS cases.

Turkey is among several destinations where European tourists had previously travelled before developing STEC 0104 infection between 2004 and $2009(n=4)$, along with Afghanistan, Egypt and Tunisia [11]. This outbreak supports data suggesting that the STEC serogroup $\mathrm{O}_{104}$ circulates in these areas. Further evidence is provided by the three additional cases that were subsequently identified in Germany and Denmark among persons also returning from Turkey within the same approximate time frame. Public health authorities and clinicians should be vigilant for possible STEC 0104 infection in individuals returning from these areas who present with post-diarrhoeal HUS.

\section{Acknowledgments}

The authors wish to acknowledge the Agence Régionale de Santé de Basse-Normandie, the Tour operator, the French tourists, Gilles Delmas, Elisabeth Couturier, Véronique Goulet, Harold Noël, Christine Campese, Dounia Bitar and Francesco Nogareda at the Institut de Veille Sanitaire for their assistance in the investigation of this outbreak. We additionally acknowledge Dirk Werber of the Robert Koch Institute in Berlin and Charlotte Kjelsø of the Statens Serum Institut in Copenhagen for sharing information on the cited German and Danish cases of STEC 0104: $\mathrm{H}_{4}$ infection.

\section{References}

1. Mariani-Kurkdjian P, Bingen E, Gault G, Jourdan-Da Silva N, Weill FX. Escherichia coli $0104: \mathrm{H}_{4}$ south-west France, June 2011. Lancet Infect Dis. 2011;11(10):732-3.

2. Bielaszewska M, Mellmann A, Zhang W, Köck R, Fruth A, Bauwens A, et al. Characterisation of the Escherichia coli strain associated with an outbreak of haemolytic uraemic syndrome in Germany, 2011: a microbiological study. Lancet Infect Dis. 2011;11(9):671-6.

3. Ribot EM, Fair MA, Gautom R, Cameron DN, Hunter SB, Swaminathan B, et al. Standardization of pulsed-field gel electrophoresis protocols for the subtyping of Escherichia coli 0157:H7, Salmonella, and Shigella for PulseNet. Foodborne Pathog Dis. 2006;3(1):59-7.

4. Monecke S, Mariani-Kurkdjian P, Bingen E, Weill FX, Balière C, Slickers $\mathrm{P}$, et al. Presence of enterohemorrhagic Escherichia coli ST678/0104:H4 in France prior to 2011. Appl Environ Microbiol. 2011;77(24):8784-6.

5. Raoult D, Dasch G. The line blot: an immunoassay for monoclonal and other antibodies. J Immunol Methods. 1989;125(1-2):57-65.

6. Frank C, Werber D, Cramer JP, Askar M, Faber M, an der Heiden $M$, et al. Epidemic Profile of Shiga-Toxin-Producing Escherichia coli $\mathrm{O}_{104}: \mathrm{H}_{4}$ Outbreak in Germany. N Engl J Med. 2011;365(19):1771-80.

7. Gault G, Weill FX, Mariani-Kurkdjian P, Jourdan-da Silva N, King $\mathrm{L}$, Aldabe B, et al. Outbreak of haemolytic uraemic syndrome and bloody diarrhoea due to Escherichia coli 0104: $\mathrm{H}_{4}$, southwest France, June 2011. Euro Surveill. 2011;16(26):pii=19905. Available from: http://www.eurosurveillance.org/ViewArticle. aspx?Articleld=19905

8. Buchholz U, Bernard H, Werber D, Böhmer MM, Remschmidt C, Wilking H, et al. German outbreak of Escherichia coli $\mathrm{O}_{104}: \mathrm{H}_{4}$ associated with sprouts. N Engl J Med. 2011;365(19):1763-70.

9. European Food Safety Authority (EFSA). Tracing seeds, in particular fenugreek (Trigonella foenum-graecum) seeds, in relation to the Shiga toxin-producing E. coli (STEC) 0104: $\mathrm{H}_{4}$ 2011 Outbreaks in Germany and France. Parma: EFSA; 5 Jul 2011. Available from: http://www.efsa.europa.eu/en/ supporting/doc/176e.pdf

10. Robert Koch Institute (RKI). Final presentation and evaluation of epidemiological findings in the EHEC 0104: $\mathrm{H}_{4}$ outbreak, Germany 2011. Berlin: RKI; Sep 2011. Available from: http:// www.rki.de/cln_109/nn_217400/EN/Home/EHEC final rep ort,templateld=raw, property $=$ publicationFile.pdf/EHEC_final_ report.pdf

11. European Centre for Disease Prevention and Control (ECDC) / European Food Safety Authority (EFSA). Shiga toxin/verotoxinproducing Escherichia coli in humans, food and animals in the EU/EEA, with special reference to the German outbreak strain STEC 0104. Stockholm: ECDC; Jun 2011. Available from: http:// ecdc.europa.eu/en/publications/Publications/1106_TER_EColi_ joint_EFSA.pdf 